Journal of Patient-Centered

\title{
Financial Conflicts of Interest Change After a High-Impact Clinical Trial Publication in Oncology
}

Craig L. Cambridge

Emily Stern Gatof

Glen J. Weiss

Roger B. Davis

Follow this and additional works at: https://aah.org/jpcrr

Part of the Bioethics and Medical Ethics Commons, Oncology Commons, and the Other Medicine and Health Sciences Commons

\section{Recommended Citation}

Cambridge CL, Gatof ES, Weiss GJ, Davis RB. Financial conflicts of interest change after a high-impact clinical trial publication in oncology. J Patient Cent Res Rev. 2020;7:249-54. doi: 10.17294/

2330-0698.1735

Published quarterly by Midwest-based health system Advocate Aurora Health and indexed in PubMed Central, the Journal of Patient-Centered Research and Reviews (JPCRR) is an open access, peer-reviewed medical journal focused on disseminating scholarly works devoted to improving patient-centered care practices, health outcomes, and the patient experience. 


\title{
Financial Conflicts of Interest Change After a High-Impact Clinical Trial Publication in Oncology
}

\author{
Craig L. Cambridge, MD, ${ }^{1}$ Emily Stern Gatof, MD, ${ }^{2}$ Glen J. Weiss, MD, MBA, ${ }^{2,3}$ Roger B. Davis, ScD ${ }^{3}$ \\ ${ }^{1}$ Facultad de Medicina, Universidad Francisco Marroquín, Guatemala City, Guatemala; ${ }^{2}$ Department of Medicine, \\ Beth Israel Deaconess Medical Center, Boston, MA; ${ }^{3}$ Beth Israel Deaconess Medical Center/Harvard Medical School, \\ Boston, MA
}

Purpose Because financial conflicts of interest (FCOIs) may potentially influence patient care, hospital drug formularies, and treatment guidelines, it is important that these are disclosed. The purpose of this observational study was to quantify the changes in FCOI among U.S.-based academic authors in industry-sponsored oncology trials after a high-impact publication.

Methods A list of all U.S.-based academic authors (authors) of industry-sponsored solid tumor clinical trials published between August 1, 2014, and December 31, 2015, in 6 high-impact journals (New England Journal of Medicine, Nature, Science, Lancet Oncology, Journal of Clinical Oncology, and Cancer Discovery) was assembled. Studies were limited to solid tumor oncology trials. After all authors were identified, direct and research funding was tabulated from CMS Open Payments for the year prior (Ypre) and the first 3 years following publication (Y1, Y2, Y3) in the high-impact journal. Summary statistics were tabulated and repeated-measures linear mixed-effects regression models were fit to examine changes after publication.

Results A total of 102 publications with a total of 620 authors were identified. No FCOI was declared by 11, 12, 21, and 24 authors in Ypre, Y1, Y2, and Y3, respectively. In Ypre, Y1, Y2, and Y3: median FCOI for direct payments was $\$ 16,702$ (range: $\$ 0-\$ 3,180,356$ ), $\$ 20,830$ (range: $\$ 0-\$ 3,180,356$ ), $\$ 22,031$ (range: $\$ 0-\$ 920,746$ ), and $\$ 21,356$ (range: $\$ 0-\$ 920,707$ ), respectively; while median research funding was $\$ 559,202$ (range: $\$ 0-\$ 19,973,818$ ), $\$ 505,031$ (range $\$ 0-\$ 19,920,452$ ), $\$ 502,726$ (range: $\$ 0-\$ 15,729,776$ ), and $\$ 497,342$ (range: $\$ 0-\$ 43,036,716$ ), respectively. There were nonsignificant increases in total direct payments and total direct payments received from the sponsor ( $P>0.0125$ for both) and statistically significant decreases in total associated research funding and total research funding from the research sponsor in $Y 1, Y 2$, and $Y 3$ as compared to Ypre ( $P<0.0001$ for both).

Conclusions After publication of an industry-sponsored solid tumor clinical trial in a high-impact journal, authors had statistically significant decreases in research funding FCOI in the first 3 years postpublication compared to the year prior. (J Patient Cent Res Rev. 2020;7:249-254.)

Keywords clinical trials; financial conflicts of interest; oncology; CMS Open Payments

$\mathrm{F}$ inancial conflicts of interest (FCOIs) are known to be prevalent across medical disciplines, with the potential to influence hospital drug formularies, treatment guidelines, meta-analyses,

Correspondence: Glen J. Weiss, MD, MBA,

200 Cambridgepark Dr., Suite 3100, Cambridge, MA 02140

(drglenweiss@outlook.com) diagnostic criteria, and outcomes reporting. ${ }^{1-7}$ International findings report that FCOIs with drug companies may influence drug recommendations and are common among guideline-writing authors. ${ }^{8}$ FCOI is a major area of concern in the field of oncology, as it may introduce actions that bias clinical trial results, reduce objectivity, and influence cancer treatment recommendations..$^{8-10}$ One-third of oncology authors do not fully disclose all payments received from the sponsor of the published clinical trial, ${ }^{10}$ which is 
alarming considering the potential influence this may have on the messaging within the trial publication. The evidence presented in that oncology study is of concern because other studies have reported at least some degree of altered behavior whenever there is interaction with drug companies. ${ }^{1-9}$ This can pose negative consequences, including prescription of more costly medication without additional benefit or with marginal benefit of that treatment. Physicians also may be blinded by unconscious bias from matching the treatment most likely to benefit the patient.

To help improve transparency, a free online tool called CMS Open Payments reports industry payments to U.S.-based practitioners. ${ }^{11}$ Its limitations are that it is restricted to companies that have activities in the United States and have a drug or product in the United States that is reimbursed by Children's Health Insurance Program, Medicare, or Medicaid. Thus, neophyte companies sponsoring clinical trials that do not have a commercial product or commercial test are not required to disclose payments until a date after drug or test approval. Many health centers have FCOI policies. ${ }^{12}$ However, few promote complete transparency. The University of Texas Southwestern Medical Center (Dallas, TX) allows public access to its FCOI database. Washington University in St. Louis (St. Louis, MO) publishes information on any industry relationship that nets a physician more than $\$ 10,000$ annually on its medical practice website. Others, such as Mayo Clinic (Rochester, MN) and Dana-Farber Cancer Institute (Boston, MA) allow public access to FCOIs upon request.

The primary objective of this observational research analysis was to investigate if there was an increase in direct payments or research funding to an author subsequent to the year of publication of an oncology clinical trial in a high-impact journal.

\section{METHODS}

Two independent reviewers searched for prospective anticancer intervention studies that covered solid tumors, were phase I-III clinical trials, and were published (online or in print) in 1 of 6 high-impact journals: New England Journal of Medicine, Nature, Science, Lancet Oncology, Journal of Clinical Oncology, and Cancer Discovery. The review was conducted from July 2018 to December 2018, with an update in December 2019 following journal peer review. Only industry-sponsored trials were included. Studies sponsored by national cancer agencies or cooperative groups were excluded.

Once a study was identified, all of the listed authors who met inclusion criteria were recorded in an Excel spreadsheet. Authors had to be physicians based in the United States, as the disclosure clause only applies to practicing doctors. Authors had to be either an oncologist, oncologic surgeon, dermatologist, or neuro-oncologist who did not have an industry sponsor as their primary affiliation. Pathologists, urologists, radiologists, and radiation oncologists were excluded as these specialties typically do not prescribe or administer systemic oral or intravenous chemotherapy. Financial disclosure information for all the identified authors was collected from CMS Open Payments (https://www.cms.gov/ OpenPayments/Explore-the-Data/Dataset-Downloads. html). All payments posted were considered FCOI. Sponsor funding from related entities (eg, Genentech and Genentech USA) was combined.

The financial information recorded included: total direct payments, total associated research funding, total direct payments received from the sponsor, and the total research funding received from the research sponsor. Total direct payment was defined as any payment received by the author for a given year. Total associated research funding for a given year was defined as all research-related funding paid directly to the author or to the author's institution in support of studies for which the author was the principal investigator. Total direct payment received from the sponsor was defined as any direct payments from the sponsor of the trial for which the author was listed for a given year. Total research funding received from the sponsor was any researchrelated funding paid to the author or the author's institution from the sponsor of the trial for which the author was listed for a given year.

Data for these four categories were collected for the 365 days immediately preceding the publication date (Ypre), day of publication up to 1 year postpublication (Y1), end of Y1 to 2 years postpublication (Y2), and end of Y2 to 3 years postpublication (Y3). Since CMS Open Payment periods during this investigation covered August 1, 2013, through December 31, 2018, only e-publication or print publications posted between August 1, 2014, and December 31, 2015, were included 
to allow for Y3 follow-up. Financial data from CMS Open Payments was pulled and categorized as Ypre, Y1, $\mathrm{Y} 2$, or $\mathrm{Y} 3$, respectively, relative to the publication date.

Distributions of the payment values were examined and summary information (medians, means, minimum and maximum values) presented. The distributions were highly skewed, as is typical for this type of data. ${ }^{13}$ To moderate the influence of extreme values, logarithmic transformations of the outcome measures were used to model the association with time period. Reported payments of zero dollars were assigned a logarithmic value of zero. This transformation substantially reduced the skewness of the distributions. Linear mixed-effects models were fit to the data. For each outcome, the dependent variable of interest was the logarithmic-transformed payment, treated as repeated measures (ie, the four time periods), for each author. The independent variable of interest was the time period (as a categorical variable). The manuscript was treated as a random effect in the model. An autoregressive covariance structure was used, as it fit the data better than compound symmetry based on the Akaike information criterion. ${ }^{14}$

For each model, the estimated percentage change in payments for $\mathrm{Y} 1, \mathrm{Y} 2$, and $\mathrm{Y} 3$ relative to Ypre is reported, along with the corresponding 95\% confidence interval. A P-value comparing the three postpublication time periods also is reported. To preserve a global 5\% level of significance, a Bonferroni approach was implemented and P-values less than 0.0125 were considered statistically significant. The Bonferroni approach is a standard statistical method for preserving a global level of significance (ie, false-positive rate and $\alpha$ ) for a study that includes multiple statistical tests. In this case, we wanted to limit the probability of a false-positive result to 0.05 across 4 statistical tests, so we set the level of significance to 0.0125 (ie, $0.05 / 4$ ) for each test.

\section{RESULTS}

A total of 102 publications with a total of 620 authors were identified (complete data set available from corresponding author by request). No FCOI was declared by 11, 12, 21, and 24 authors in Ypre, Y1, Y2, and Y3, respectively. In Ypre, Y1, Y2, and Y3, respectively, the median FCOI for direct payments was $\$ 16,702$ (range: $\$ 0-\$ 3,180,356$ ), $\$ 20,830$ (range: $\$ 0-\$ 3,180,356$ ), $\$ 22,031$ (range: $\$ 0-\$ 920,746$ ), and \$21,356 (range: \$0-\$920,707). In Ypre, Y1, Y2, and Y3, respectively, the median research funding was $\$ 559,202$ (range: $\$ 0-\$ 19,973,818$ ), $\$ 505,031$ (range: $\$ 0-\$ 19,920,452), \$ 502,726$ (range: $\$ 0-\$ 15,729,776$ ), and $\$ 497,342$ (range: $\$ 0-\$ 43,036,716$ ).

Results of the regression models are shown in Tables 1 and 2. There were increases in total direct payments $(\mathrm{P}=0.024)$ and total direct payments received from the sponsor $(\mathrm{P}=0.033)$ in $\mathrm{Y} 1, \mathrm{Y} 2$, and $\mathrm{Y} 3$ as compared to Ypre, though these increases did not reach the prespecified threshold for statistical significance of $\mathrm{P}<0.0125$. Total associated research funding and total research funding from the research sponsor were significantly decreased in Y1, Y2, and Y3 compared to Ypre ( $\mathrm{P}<0.0001$ for both). Relative to Ypre, direct payments increased by $26.4 \%$ in $\mathrm{Y} 1,25.2 \%$ in $\mathrm{Y} 2$, and $8 \%$ in $\mathrm{Y} 3$, while total direct payments received from the sponsor increased by $32.9 \%$ in $\mathrm{Y} 1,40.5 \%$ in $\mathrm{Y} 2$, and $12.4 \%$ in Y3. Relative to Ypre, total associated research funding decreased by $9.1 \%$ in $\mathrm{Y} 1,30.9 \%$ in

Table 1. Regression Model ${ }^{*}$ Results

\begin{tabular}{lcccc}
\hline & \multicolumn{4}{c}{ Outcome } \\
\cline { 2 - 5 } Measure & $\begin{array}{c}\text { Direct } \\
\text { payments }\end{array}$ & $\begin{array}{c}\text { Research } \\
\text { funding }\end{array}$ & $\begin{array}{c}\text { Direct payments } \\
\text { from sponsor }\end{array}$ & $\begin{array}{c}\text { Research funding } \\
\text { from sponsor }\end{array}$ \\
\hline Y1 percentage change & $26.4(7.5,48.7)$ & $-9.1(-23.5,7.9)$ & $32.9(5.9,66.7)$ & $-32.0(-49.0,-9.4)$ \\
Y2 percentage change & $25.2(2.4,52.9)$ & $-30.9(-44.1,-14.4)$ & $40.5(7.1,84.4)$ & $-60.8(-72.4,-44.5)$ \\
Y3 percentage change & $8.0(-12.1,32.7)$ & $-47.6(-57.9,-34.7)$ & $12.4(-14.6,47.9)$ & $-72.0(-80.4,-60.0)$ \\
P-value & 0.024 & $<0.0001$ & 0.033 & $<0.0001$ \\
\hline
\end{tabular}

${ }^{*}$ A repeated measures, linear mixed-effects model with time point as a fixed effect and manuscript as a random effect. The outcome measures were logarithmic transformations. Percentage changes (with confidence interval in parentheses) are relative to the year prior to publication. The P-value tests whether the three time periods had equal payments. 
Table 2. Mean and Median Values for Each FCOI Category

\begin{tabular}{|c|c|c|}
\hline & Mean \pm SD & Median (Q1-Q3) \\
\hline \multicolumn{3}{|c|}{ Direct payments } \\
\hline Ypre & $\$ 45,338 \pm \$ 207,813$ & $\$ 16,702(\$ 2802-\$ 41,430)$ \\
\hline Y1 & $\$ 42,859 \pm \$ 138,427$ & $\$ 20,829(\$ 4368-\$ 44,928)$ \\
\hline Y2 & $\$ 42,989 \pm \$ 74,973$ & $\$ 22,031(\$ 4751-\$ 51,980)$ \\
\hline Y3 & $\$ 44,405 \pm \$ 78,549$ & $\$ 21,356(\$ 3887-\$ 50,959)$ \\
\hline \multicolumn{3}{|c|}{ Research funding } \\
\hline Ypre & $\$ 1,149,739 \pm \$ 1,951,608$ & $\$ 559,203(\$ 133,175-\$ 1,377,822)$ \\
\hline Y1 & $\$ 1,230,219 \pm \$ 2,185,201$ & $\$ 505,031(\$ 128,641-\$ 1,506,445)$ \\
\hline Y2 & $\$ 1,093,947 \pm \$ 1,715,387$ & $\$ 502,726(\$ 115,240-\$ 1,344,879)$ \\
\hline Y3 & $\$ 1,162,986 \pm \$ 2,313,992$ & $\$ 497,342(\$ 72,059-\$ 1,419,730)$ \\
\hline \multicolumn{3}{|c|}{ Direct payments from sponsor } \\
\hline Ypre & $\$ 14,301 \pm \$ 171,260$ & $\$ 0(\$ 0-\$ 3944)$ \\
\hline Y1 & $\$ 6587 \pm \$ 26,076$ & $\$ 0(\$ 0-\$ 4508)$ \\
\hline Y2 & $\$ 5525 \pm \$ 12,586$ & $\$ 0(\$ 0-\$ 5867)$ \\
\hline Y3 & $\$ 4642 \pm \$ 10,948$ & $\$ 0(\$ 0-\$ 4867)$ \\
\hline \multicolumn{3}{|c|}{ Research funding from sponsor } \\
\hline Ypre & $\$ 199,030 \pm \$ 473,630$ & $\$ 8189(\$ 0-\$ 182,849)$ \\
\hline Y1 & $\$ 213,880 \pm \$ 641,705$ & $\$ 2865(\$ 0-\$ 149,810)$ \\
\hline Y2 & $\$ 152,262 \pm \$ 629,739$ & $\$ 237(\$ 0-\$ 113,998)$ \\
\hline Y3 & $\$ 225,868 \pm \$ 1,712,224$ & $\$ 0(\$ 0-\$ 88,714)$ \\
\hline
\end{tabular}

FCOI, financial conflict of interest; Q1, 25th percentile; Q3, 75th percentile; SD, standard deviation; Ypre, the time period 365 days immediately preceding publication date; Y1, day of publication to 1 year postpublication; Y2, second year after publication; Y3, third year after publication.

$\mathrm{Y} 2$, and $47.6 \%$ in $\mathrm{Y} 3$, while total associated research funding from the research sponsor decreased by $32 \%$ in $\mathrm{Y} 1,60.8 \%$ in $\mathrm{Y} 2$, and $72 \%$ in $\mathrm{Y} 3$.

\section{DISCUSSION}

Ethically speaking, FCOIs may have a negative effect on research and publication. They can, perhaps unconsciously, bias moral judgment when developing arguments in an area of scientific or clinical research or regarding health policy. ${ }^{15}$ FCOIs also are of great clinical significance due to their potential to influence a physician's choice in therapy. Physicians who occasionally accepted a sponsored meal from a pharmaceutical company were 2 to 3 times more likely to request that drug company's product be placed on a hospital's drug formulary. ${ }^{16}$

The data presented herein show an ongoing financial relationship between sponsors and authors after publication. Some examples of ongoing relationships may include serving on speaker's bureaus or advisory boards, participation in investigator's meetings, or serving as investigators on future trials. While it may seem intuitive that increased accrual and funding to the institution go hand in hand with the conduct and oversight of a clinical trial, this study did not just look at institutional funding. It also incorporated the aggregation of total direct payments, which includes promotional speaking and/or consulting from sources that are required to report to CMS Open Payments. It is important to note that when self-reporting their FCOI, nearly two-thirds of oncologists have discordant disclosures between a clinical trial abstract and the subsequent full manuscript publication of that clinical trial. ${ }^{17}$ The prevalence of FCOI discordance is maintained among authors in American Society of Clinical Oncology publications and/or conference presentations and their associated disclosures posted on CMS Open Payments. ${ }^{18}$

We chose to analyze solid tumors, as this is the primary focus of medical oncology. Treatment for medical oncology patients is primarily administered 
in outpatient clinics and/or standalone cancer centers and is the expertise of one of the authors. In contrast, hematologists specializing in the treatment of patients with hematologic malignancies more commonly administer treatment in an inpatient setting. This difference in care delivery would likely result in differences in direct payments and research funding.

After publication of an industry-sponsored solid tumor clinical trial in a high-impact journal, authors had nonsignificant increases in FCOI (direct payments and sponsor of trial direct payments). Surprisingly, there were significant decreases in research funding and sponsor of trial research funding FCOI in the first 3 years postpublication compared to the year prior. Several possibilities could explain this decrease in research funding for the identified authors in this analysis. These include but are not limited to: 1) diminished research funding due after publication of the high-impact study; 2) identified authors may not be the lead investigators for their institution in subsequent studies that incur research funding; 3) the identified authors may have decreased their research activities; or 4) the identified authors are lead investigators on studies with sponsors that do not meet the criteria for reporting payments to CMS Open Payments.

Other areas for future exploration include examining FCOI changes before and after a pivotal trial among authors outside of oncology. Are those changes commensurate with the relationships observed in medical oncology? What areas of oncology research do we observe peaks and valleys of FCOI over time?

\section{Limitations}

There are some limitations of our study. Research funding to the author institutions could be delayed and fall on the years subsequent to the publication and influence the results. In addition, funding may be underreported from companies that are exempt from CMS Open Payment reporting. Nearly 10\% of authors had no funding in CMS Open Payments during one of the time points, and a small fraction of authors were outliers with significant funding. Thus, to alleviate the skewness, logarithmic transformation was required. The linear mixed-effects model essentially looks at the change in logarithmic payments from Ypre to Y1 to Y2 to Y3 for each author and averages those changes across the authors. If increases were only happening for a small subset of the authors, the differences would not be statistically significant. Due to small numbers and potential limitations of multiple hypothesis testing, we did not perform additional analyses with respect to the number of funding sources, primary endpoint of trial being met, or the author position on the publication. Other limitations of the CMS Open Payments database include the potential inaccuracy of FCOI reporting attributed to a physician and short deadlines to remedy an error. If no FCOI is declared in the CMS Open Payments database, this means that the investigator has no FCOI that qualifies for reporting in the database. These investigators still may have FCOI with entities that are not legally required to report, but those influences on hospital drug formulary and treatment guidelines are minimal or unlikely to be relevant at the time of the publication.

A potential remedy to more accurately reflect FCOI would be for journals to require, upon acceptance of a manuscript, that authors with social media profiles provide a link to their FCOI or declare it in their announcements or "likes" to links related to their publication or subsequent sponsor-related talks/ promotions for a period of 24 months postpublication. ${ }^{19}$ Another option would be to make the contracts between authors and industry sponsors available to the public.

\section{CONCLUSIONS}

The purpose of this observational study was to report if there was an increase in direct payments or research funding to an author subsequent to the year of publication of an oncology clinical trial in a highimpact journal. We observe that authors of industrysponsored solid tumor clinical trials published in high-impact journals had statistically significant decreases in research funding FCOI in the first 3 years postpublication compared to the year prior.

There are various studies that demonstrate that FCOIs between industry and physicians have influenced physician behavior and patient care, either directly or indirectly. FCOIs should be disclosed and managed, ideally in a uniform and transparent manner. Overall, there remains a number of unanswered questions and opportunities to further explore, not just in oncology, but within and across other medical disciplines. 


\section{Patient-Friendly Recap}

- Financial conflicts of interest have the potential to influence the work of physicians and researchers. Thus, in the United States, lead investigators of clinical trials must disclose these relationships.

- The authors analyzed disclosures from a federal database to determine if payments to oncology investigators or their institutions changed substantially after results from major clinical trials had been published.

- The authors found that research funding to these investigators actually decreased in the 3 years following publication, and they offer possible explanations for their findings.

\section{Author Contributions}

Study design: Weiss, Davis. Data acquisition or analysis: all authors. Manuscript drafting: Cambridge, Weiss, Davis. Critical revision: Weiss, Davis.

\section{Conflicts of Interest}

Dr. Weiss is currently an employee of and holds an ownership interest in Unum Therapeutics; receives consulting fees from and holds ownership interest (service provider units) in Circulogene Theranostics and MiRanostics Consulting; consults for and holds ownership in Exact Sciences Corp.; receives consulting fees from Paradigm Diagnostics, Inc., Angiex, Inc., GLG Council, Guidepoint Global, LLC, Imaging Endpoints, Spring Bank Pharmaceuticals, Inc., and IBEX Medical Analytics Ltd.; receives honoraria from Igynta, Pfizer Inc., and IDEA Pharma; receives travel and accommodation expenses from Cambridge Healthtech Institute, GlaxoSmithKline plc., and Tesaro; and holds a patent (PCT/US2011/020612) related to small cell lung cancer. The remaining authors have no competing interests.

\section{Funding Sources}

This work was conducted with support from Harvard Catalyst/The Harvard Clinical and Translational Science Center (Boston, MA) through a National Institutes of Health Award (UL1 TR002541) and financial contributions from Harvard University (Cambridge, MA) and its affiliated academic health care centers (Harvard Medical School, Harvard T.H. Chan School of Public Health, Beth Israel Deaconess Medical Center, Boston Children's Hospital, Brigham and Women's Hospital, Dana-Farber Cancer Institute, and Massachusetts General Hospital).

\section{References}

1. Andersen M, Kragstrup J, Søndergaard J. How conducting a clinical trial affects physicians' guideline adherence and drug preferences. JAMA. 2006;295:2759-64. CrossRef
2. Chren MM, Landefeld CS. Physicians' behavior and their interactions with drug companies. A controlled study of physicians who requested additions to a hospital drug formulary. JAMA. 1994;271:684-9. CrossRef

3. Jørgensen AW, Hilden J, Gøtzsche PC. Cochrane reviews compared with industry supported meta-analyses and other meta-analyses of the same drugs: systematic review. BMJ. 2006;333(7572):782. CrossRef

4. Cosgrove L, Krimsky S, Vijayaraghavan M, Schneider L. Financial ties between DSM-IV panel members and the pharmaceutical industry. Psychother Psychosom. 2006;75:154-60. CrossRef

5. Melander H, Ahlqvist-Rastad J, Meijer G, Beermann B. Evidence b(i)ased medicine - selective reporting from studies sponsored by pharmaceutical industry: review of studies in new drug applications. BMJ. 2003;326(7400):1171-3. CrossRef

6. Peppercorn J, Blood E, Winer E, Partridge A. Association between pharmaceutical involvement and outcomes in breast cancer clinical trials. Cancer. 2007;109:1239-46. CrossRef

7. Perlis RH, Perlis CS, Wu Y, Hwang C, Joseph M, Nierenberg AA. Industry sponsorship and financial conflict of interest in the reporting of clinical trials in psychiatry. Am J Psychiatry. 2005;162:1957-60. CrossRef

8. Shnier A, Lexchin J, Romero M, Brown K. Reporting of financial conflicts of interest in clinical practice guidelines: a case study analysis of guidelines from the Canadian Medical Association Infobase. BMC Health Serv Res. 2016;16(a):383. CrossRef

9. Rochon PA, Sekeres M, Hoey J, et al. Investigator experiences with financial conflicts of interest in clinical trials. Trials. 2011;12(1):9. CrossRef

10. Wayant C, Turner E, Meyer C, Sinnett P, Vassar M. Financial conflicts of interest among oncologist authors of reports of clinical drug trials. JAMA Oncol. 2018;4:1426-8. CrossRef

11. Agrawal S, Brown D. The Physician Payments Sunshine Act - two years of the Open Payments program. N Engl J Med. 2016;374:906-9. CrossRef

12. Palmer R. Teaching hospitals urged to disclose clinical conflicts of interest. Nat Med. 2010;16:836. CrossRef

13. Arnau J, Bono R, Blanca MJ, Bendayan R. Using the linear mixed model to analyze nonnormal data distributions in longitudinal designs. Behav Res Methods. 2012;44:1224-38. CrossRef

14. Harrell FE Jr. Regression Modeling Strategies: With Applications to Linear Models, Logistic Regression, and Survival Analysis. New York, NY: Springer-Verlag New York, 2001. CrossRef

15. Romain PL. Conflicts of interest in research: looking out for number one means keeping the primary interest front and center. Curr Rev Musculoskelet Med. 2015;8:122-7. CrossRef

16. Wazana A. Physicians and the pharmaceutical industry: Is a gift ever just a gift? JAMA. 2000;283:373-80. 당ssef

17. Weiss GJ, Davis RB. Discordant financial conflicts of interest disclosures between clinical trial conference abstract and subsequent publication. PeerJ. 2019;7:e6423. CrossRef

18. Garrett-Mayer E, Kaltenbaugh MW, Spence R, et al. Discrepancies in financial self-disclosures and Open Payments reporting among authors of clinical oncology research studies. J Clin Oncol. 2020;38:480-7. CrossRef

19. Tao DL, Boothby A, McLouth J, Prasad V. Financial conflicts of interest among hematologist-oncologists on Twitter. JAMA Intern Med. 2017;177:425-7. CrossRef

(C) 2020 Aurora Health Care, Inc. 